\title{
REMOVAL OF 123 NAILS FROM STOMACH OF A SCHIZOPHRENIC PATIENT:
} A RARE CASE REPORT

\author{
Sandeep Chandrakar1, Manju Singh², Amit Agrawal'3 , Gambheer Singh ${ }^{4}$
}

\section{HOW TO CITE THIS ARTICLE:}

Sandeep Chandrakar, Manju Singh, Amit Agrawal, Gambheer Singh. "Removal of 123 Nails from Stomach of a Schizophrenic Patient: A Rare Case Report". Journal of Evolution of Medical and Dental Sciences 2015; Vol. 4, Issue 50, June 22; Page: 8770-8773, DOI: 10.14260/jemds/2015/1270

\begin{abstract}
Foreign body ingestion is a commonly seen incident in emergency room, usually in children, mentally impaired and alcoholics. We are presenting a case of 48 year old schizophrenic male patient who ingested 123 iron nails requiring surgical removal. The interesting feature was absence of any serious complication even after 2 years of continuous ingestion of nails. In our knowledge this was the third heaviest ingestion of metallic nails from stomach in last 10 year literature.
\end{abstract}

KEYWORDS: Foreign body, Schizophrenia, Gastrotomy.

INTRODUCTION: Foreign body ingestion is a commonly seen incident in a emergency room usually in children (about $80 \%$ cases).(1) When encountered in adults usually patient is edentulous or has a psychiatric history (schizophrenia) or is a prison inmate.(2)

According to literature $90 \%$ of foreign bodies pass through Gastrointestinal tract without complication, only 10 to $20 \%$ necessitate removal.(3)

Sharp or pointed objects usually require removal as they may cause perforation, hemorrhage and if metallic can cause toxicity on absorption. $(4,5,6)$

A 10 year review of literature revealed only 2 cases of such large sized foreign body removal from stomach in living patient without any grave complications.

We are presenting our case as third reported case with such large size of foreign body removed from stomach of living patient.

CASE HISTORY: A 48 year old married man presented in surgical outpatient department at Dr. B.R. Ambedkar Hospital Raipur with complains of: pain in upper abdomen and vomiting soon after taking food. Pain was localized in epigastrium which was continuous throughout the day, aggravated on taking food and relieved after vomiting. The vomitus consisted of undigested food particles.

Patient's attendants gave history of patient being schizophrenic for last 15 to 20 years for which he was on psychiatric medication since then. He developed tendency of eating foreign substances since last 2 years.

On Examination: Patient was anemic, had generalized edema with mild tenderness in abdomen and no other abdominal signs. The abdominal skiagram showed radioopaque shadow in upper abdomen identical to the shape of stomach.

Upper gastrointestinal Endoscopic examination revealed a bunch of nails, both straight and curved of various sizes. Few of these nails were studded in the stomach.

Routine battery of blood and urine investigations showed hemoglobin $9 \mathrm{gm} / \mathrm{dl}$, serum sodium $133 \mathrm{mmol} / \mathrm{l}$, serum potassium $3 \mathrm{mmol} / \mathrm{l}$, total protein $3.7 \mathrm{gm} / \mathrm{dl}$, albumin $1.3 \mathrm{gm} / \mathrm{dl}$. 
Other investigations were within normal limits. The deranged electrolytes were corrected and proteins along with albumin were supplemented. Patient was then planned for surgery.

On laparotomy stomach was found lying posteriorly due to the weight of the nails. Gastrotomy was made and iron nails both straight and curved of different sizes mixed with food particles were found lying in the stomach. All the nails were removed carefully. They were 123 in number; the largest one was 8 inches long. The mucosa of stomach was hypertrophied with ulceration of size of about $1 \mathrm{~cm}$ diameter in body of stomach. A biopsy from ulcer was taken. Perigastric lymphadenopathy was also present and one such lymphnode was excised and sent for histopathological examination. There was surprisingly no perforation anywhere in stomach and rest of the gastrointestinal tract was also found normal.

Post-operative Period: It was largely uneventful except hypoprotienemia and mild electrolyte disturbances which were corrected. Biopsy report from mucosa showed hyperplastic changes and granulation tissue with chronic inflammatory cells, fibrosis and a focal area of hemorrhage.

Patient was discharged on $12^{\text {th }}$ postoperative day without any wound complications.

DISCUSSION: This patient provides an insight into the diversity of clinical manifestation in presentation of metallic foreign body in stomach and schizophrenia. The craving for eating inedible substances is common in schizophrenia. (7)

The uniqueness of this case is the size and number of iron nails that remained in stomach for such a long time without causing any acute and serious complication. Most of the literature repots intestinal obstruction, perforation peritonitis and even death among patients of schizophrenia with such a presentation. Such presentation as reported above in very uncommon. $(4,5,6)$

Prolonged retention of an object in stomach is usually related to its shape and size. Foreign bodies thicker than $2 \mathrm{~cm}$ and longer than $5 \mathrm{~cm}$ are unlikely to pass through pylorus spontaneously. Sharp objects that stay in the same place for more than 2 or 3 days or objects in the stomach that have not moved for more than 5 to 6 days are unlikely to pass spontaneously and should be removed surgically or endoscopically. ${ }^{(8,9,10)}$ Young et al described an endoscopic technique using double channel gastroscope and two wire loop snares to remove a dinner fork from stomach.(11) On the other hand Bakaleinik has suggested that all sharp and pointed objects be removed by gastrotomy rather than to attempt endoscopic means as in our case.(12)

Unlike most of the literature in which foreign bodies were a postmortem finding, $(4,5,6,7)$ this patient survived well after foreign body removal. Although it is impossible to exactly pin point the cause of abnormal eating behavior in schizophrenic patients, a possible explanation is the patients bizarre illusions and possible altered visceral and taste sensations. 


\section{CASE REPORT}

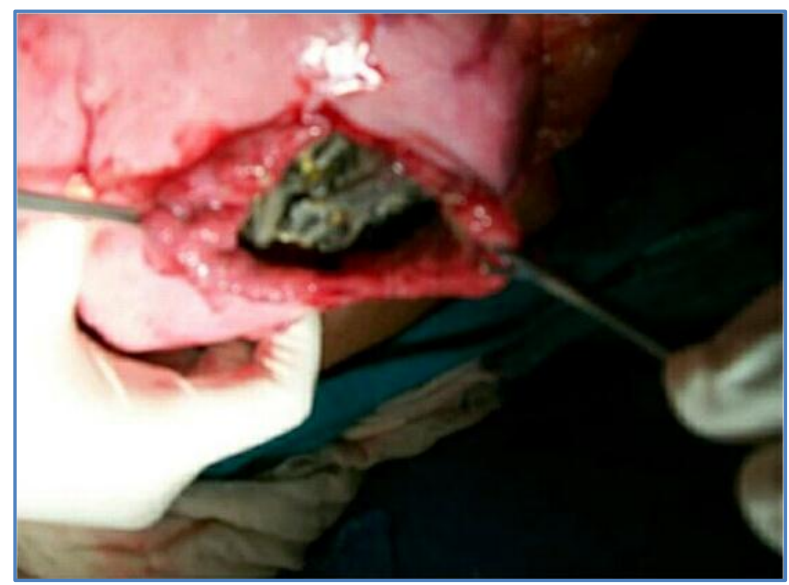

Fig. 1: Gastrotomy showing iron nails

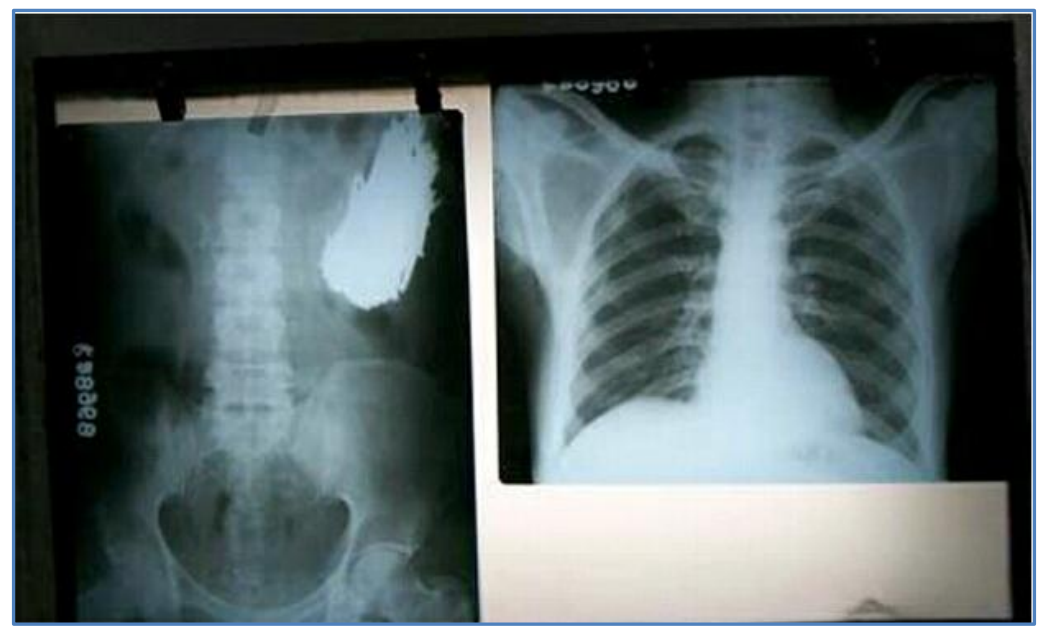

Fig. 2: X-Ray Showing Opacity - iron nails in Stomach

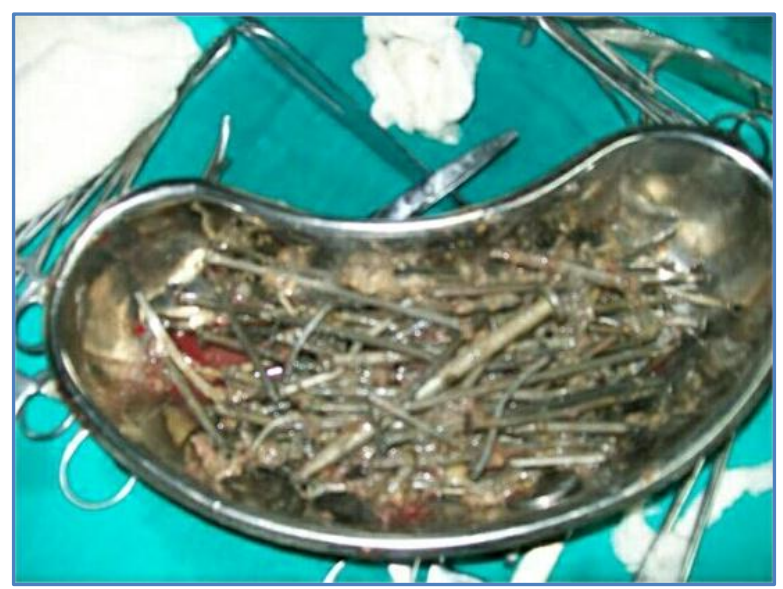

Fig. 3: Extracted nails from stomach 


\section{REFERENCES:}

1. Velitch Kov NG, Cigorov GI, Losa Moff JE et al. Ingested F.B. of the GI tract restrospective analysis of 542 cases. World J Surg. 1996; 20; 1001-05.

2. Somya Basu, Subhash C gupta, Syeed Akhtar. Massive ingestion of foreign bodies by a patient with schizophrenia. Hong Kong J Psychiatry. 2003; 13(2); 26-28.

3. Barros JL, Caballero A, Rueda JC, Monturiol JM. Foreign body ingestion - management of 167 cases. World J Surg. 1991; 15; 783-8.

4. Brian KP Goh, Pierie KH Chow, Hak Mein Quah, Hock Soo Ong. Perforation GI tract secondary to ingestion of foreign bodies; World J Surg; 2006; 30(3); 372-77.

5. Beumet DR, Baerid CJ, Chank M et al. Zinc toxicity following massive coin ingestion 261 coin. AMJ Forensic med pathology. 1997: 18: 1448-53.

6. Jacob B, Huckenberg W, Barz J, Bonte W. Death after swallowing a large number of foreign bodies (422) in schizophrenic woman. American Journal of Forensic Medicine and Pathology. 1990; 11(4); 331-5.

7. Han SY, MC Elvein R.B, Aldrete JS. Compulsive ingestion of foreign bodies in a schizophrenic patient. South med J. 1984; 77; 784-786.

8. Mandall GA, Roserbery HK. Prolong retention of F.B. in stomach. Pediatric; 1997; 60; 480-2.

9. Zhang S, Cui Y, Gong X, Gu F, Chen M, Zhong B. Endoscopic management of F.B. in upper GI tract in south china - a retrospective study of 561 cases. Digestive disease \& sciences; 2010; 55(5); 1305-12.

10. Selivano V, Sheldon GF, Cello JP, Cran RA. Management of foreign body ingestion. Ann surg 1984; 199; 187-191.

11. Young PTL, The $\mathrm{CH}$, Look M, Wee SB, Tan JCH, Chew SP. Removal of a dinner fork from stomach by double snare endoscopic extraction. Hong Kong med J. 2000; 6; 319-321.

12. Bakaleinik M. foreign bodies of gastrointestinal tract: surgical consideration. Mil Med. 1989; 154: 11-14.

\section{AUTHORS:}

1. Sandeep Chandrakar

2. Manju Singh

3. Amit Agrawal

4. Gambheer Singh

\section{PARTICULARS OF CONTRIBUTORS:}

1. Assistant Professor, Department of General Surgery, Pt. JNM Medical College, Raipur.

2. Associate Professor, Department of General Surgery, Pt. JNM Medical College, Raipur.

FINANCIAL OR OTHER COMPETING INTERESTS: None
3. Assistant Professor, Department of General Surgery, Pt. JNM Medical College, Raipur.

4. Managing Director, Samarpan Hospital, Raipur.

\section{NAME ADDRESS EMAIL ID OF THE CORRESPONDING AUTHOR:}

Dr. Amit Agrawal,

HIG - C/72, Shailendra Nagar,

Raipur - 492001, Chhattisgarh.

E-mail: doc.amitagrawal@gmail.com

Date of Submission: 31/05/2015.

Date of Peer Review: 01/06/2015.

Date of Acceptance: 15/06/2015.

Date of Publishing: 22/06/2015. 